\title{
Conditioned fear assessed by freezing and by the suppression of three different baselines
}

\author{
MARK E. BOUTON and ROBERT C. BOLLES \\ University of Washington, Seattle, Washington 98195
}

\begin{abstract}
Rats received either forward or backward pairings of an auditory CS and shock. They were then tested for conditioned suppression to the CS while barpressing for food, licking a sucrose solution, or being spontaneously active. Behavior was simultaneously observed using a timesampling method. In each case, forward-conditioned animals exhibited more freezing than controls, and freezing was reliably correlated with suppression of the baseline. These results suggest that the different loss-of-baseline measures of aversive conditioning reflect the amount of defensive behavior evoked by the CS. They also suggest the utility of freezing as an index of conditioning. Freezing assayed by the time-sampling method was comparable to the more conventional indices of conditioning in sensitivity to the effects of conditioning.
\end{abstract}

The rat has a defensive behavior repertory that it draws upon when it is presented with cues (CSs) that are paired with shock. When the CS is a localized visual cue, the rat may withdraw from it (Karpicke, Christoph, Peterson, \& Hearst, 1977). When the animal is shocked by a prod extending from the wall of a chamber, the rat may bury the prod with sawdust if sawdust is available (e.g., Pinel \& Treit, 1978). However, in small, barren chambers such as the ones that are usually employed in studies of aversive conditioning, rats presented with stimuli that have been associated with shock commonly freeze or crouch (e.g., Blanchard \& Blanchard, 1969; Bolles \& Collier, 1976; Bouton \& Bolles, 1979; Fanselow \& Bolles, 1979a, 1979b; Sigmundi, Bouton, \& Bolles, 1980).

Freezing appears to be a respondent, in that it is controlled by its antecedents rather than its consequences (Bolles \& Riley, 1973). It is also influenced by several parameters of conditioning, including shock (US) intensity (Blanchard \& Blanchard, 1969; Fanselow \& Bolles, 1979a; Sigmundi et al., 1980) and CS-US interval (Davitz, Mason, Mowrer, \& Viek, 1957). Freezing occurs with more frequency to conditioned stimuli than to novel control stimuli, either when the CS is a complex of contextual cues (e.g., Blanchard \& Blanchard, 1969; Bolles \& Collier, 1976) or when nominal CSs are used (Bouton \& Bolles, 1979; Sigmundi et al., 1980). Forward-conditioned stimuli also produce more freezing than backward-conditioned controls (Fanselow \& Bolles, 1979b).

In light of this evidence, it is perhaps curious that the direct observation of freezing or of other defensive behaviors does not figure more prominently in studies of aversive conditioning. Such behaviors have been used

This research was supported by Grant BNS 76-19912 from the National Science Foundation. Reprint requests should be addressed to the first author, Department of Psychology, University of Vermont, Burlington, Vermont 05401. occasionally (e.g., Bouton \& Bolles, 1979), but more often, aversive conditioning is indexed either by the suppression of an operant baseline, such as barpressing that is supported by positive reinforcement (e.g., Estes \& Skinner, 1941), or by the suppression of consummatory behaviors such as sucrose licking (e.g., Leaf \& Muller, 1965). The use of these baselines, particularly barpressing, is justified because its suppression is lawfully related to the parameters of conditioning (e.g., Kamin, 1965). However, there has never been a consensus about what "causes" the suppression of these baselines (e.g., Blackman, 1977).

It has often been assumed that the CS evokes defensive behavior that competes with the baseline response (e.g., Kamin, 1965; McAllister \& McAllister, 1971), but this assumption is not universal. Millenson and de Villiers (1972) have taken a different view; they propose that fear generated by the CS competes with the appetitive motivation supporting the baseline. The rat stops barpressing because it is less hungry, not because it is freezing. There have been few data directly addressing the competing response issue. In their early experiments on conditioned suppression, Hunt and Brady (e.g., 1955) observed rats freezing during on-baseline conditioning. Karpicke et al. (1977) have recently reported observing rats withdrawing from a localized visual CS superimposed on an operant baseline. Stein, Hoffman, and Stitt (1971) observed a reduction in the pigeon's movement when a CS was probed on a keypecking baseline (see also Hoffman \& Barrett, 1971). However, no study has used an observational technique that would permit a look at the quantitative relation between defensive behaviors and response suppression. Empirically, we are still where we were when Millenson and de Villiers (1972) concluded that "no systematic measurements of actual incompatible responses covarying with suppression have ever been made" (p. 99). The present studies make a start in filling this gap in the literature. 


\section{EXPERIMENT 1}

The first experiment examined the relationship between freezing and the suppression of operant barpressing. Owing largely to the work of Kamin (e.g., 1965), this baseline has become the de rigeur method of measuring aversive conditioning. The standard index of suppression in the operant baseline is the suppression ratio, first introduced by Annau and Kamin (1961). The suppression ratio is the number of barpresses made during the CS divided by the number of barpresses made during both the $\mathrm{CS}$ and an equal period prior to the CS. The ratio is .50 when the baseline response rate is not changed by introduction of the $\mathrm{CS}$, while ratios greater or less than .50 indicate, respectively, enhanced responding and suppressed responding during the CS. Perhaps the greatest advantage of the suppression ratio is that it eliminates intersubject variability due to differences in baseline operant rates. On the other hand, the suppression ratio obscures potentially interesting differences in the rate of responding in the absence of the CS. And it is biased toward showing lower levels of suppression to the CS when there is overall suppression of the baseline. For these reasons, suppression ratios are sometimes supplemented or replaced with other measures of barpress suppression, such as the rate of barpressing during the CS.

\section{Method}

Subjects. The animals were 16 female rats of Wistar descent, 100 days old at the start of the experiment. They were individually housed in a room with a 12-h day-night cycle. The animals were food-deprived and maintained at $80 \%$ of their initial body weights throughout the experiment, which was conducted during the day.

Apparatus. The apparatus consisted of two conditioning boxes and four Skinner boxes. The Skinner boxes each measured $30 \times 25 \times 29 \mathrm{~cm}$. The front and back walls were aluminum; the side walls were clear acrylic plastic. Illumination was provided by a $28-\mathrm{V}$ pilot light centered in the top of the front wall. The floor consisted of $6-\mathrm{mm}$ stainless steel grids spaced $1.7 \mathrm{~cm}$ center to center. Forty-five-milligram food pellets were delivered to a recessed food cup centered in the front wall A $3.6-\mathrm{cm}$ bar was mounted $7 \mathrm{~cm}$ above the floor and to the right of the food cup. The CS (the $60-$ sec presentation of a $3,300-\mathrm{Hz}$ tone) was delivered through a speaker located above the food cup, $20 \mathrm{~cm}$ from the floor. The CS had an intensity of $84 \mathrm{~dB}$ (A scale); background noise level was $70 \mathrm{~dB}$. The animals could be observed through a side wall of the box and a window in the sound-attenuating chamber.

The conditioning boxes were each $35 \times 30 \times 30 \mathrm{~cm}$. Each was constructed of black plywood except for a clear acrylic plastic front wall, which could permit a view of the animals. Illumination was provided by a $7.5-\mathrm{W}$ bulb mounted to the center of the ceiling. The floor consisted of 9-mm stainiess steel grids spaced $1.8 \mathrm{~cm}$ center to center. The tone CS was presented at an intensity matching that in the Skinner boxes, $84 \mathrm{~dB}$. Background noise level was again $70 \mathrm{~dB}$. The US was a .5 -sec, $1-\mathrm{mA}$ scrambled footshock.

Procedure. The animals were initially bar-trained in the Skinner boxes during seven daily 60 -min sessions. During the first session, each barpress was reinforced. Over the following 2 days, the animals barpressed on VI 30-sec and VI 60-sec schedules of reinforcement. The last 4 days of bar training consisted of training on a VI 90 -sec schedule, the schedule used later in testing.

On the day following the end of bar training, the animals were given one $60-\mathrm{min}$ session in the conditioning box in which a 60 -sec presentation of the tone was paired with shock 15 times. The order in which these stimuli were paired differed between the two groups. One group, Group FC $(n=8)$, received forward conditioning such that the CS terminated with shock onset. The other group, Group BC, received backward conditioning in which the shock terminated with CS onset. For both groups, the intertrial interval varied around a mean of $3 \mathrm{~min}$. The backward control procedure was used because it exposed the animals in the control group to the same events that animals in the experimental group experienced. The backward procedure can sometimes produce a nonzero outcome, but if any such outcome were to occur with the relatively small number of trials used here, there is good reason to expect it to be marginally excitatory, rather than inhibitory (see Heth, 1976). Group BC may therefore constitute a somewhat conservative control for excitation conditioned to the CS in Group FC.

On the day following conditioning, all animals were returned to the Skinner boxes and given an additional practice session with the VI $90-\mathrm{sec}$ schedule. Testing occurred on the next day during a single $7-\mathrm{min}$ session. Each animal was tested individually in the Skinner box while barpressing on the VI $90-\mathrm{sec}$ schedule. The CS was presented without shock for $60 \mathrm{sec}$ during the 5 th minute of the session. During that minute and the $60 \mathrm{sec}$ immediately preceding it, an observer who was blind to the experimental conditions time-sampled the rats' behavior every 3 sec. Each sample was coded as freezing, barpressing, foodcup behavior, or activity (see Table 1). In order to assess the reliability of the time-sampling technique, a second "blind" observer independently sampled each rat's behavior at the same time. This second observer had not had any prior experience with the time-sampling technique and received the definitions of the behaviors as they appear in Table 1 only a few minutes before testing began.

\section{Results}

The overall correlation between the amount of freezing recorded by the primary observer and the naive observer was $r(15)=+.98$. Freezing recorded by the two observers was also highly correlated within each group [Group FC, $r(7)=+.98$; Group BC, $r(7)=+.93$ ]. These correlations are consistent with correlations we have

Table 1

Time-Sampling Categories and Descriptions

Category

Freezing Barpressing

Food-Cup Behavior Drinking Activity
Description

Body immobility and the absence of vibrissae movement associated with sniffing.

Activity in contact with the bar.

Activity in contact with the food cup.

Mouth contact with the drinking tube.

Active behaviors not falling into the other categories. 
observed when the second observer is somewhat more experienced with the time-sampling technique (Bouton \& Bolles, 1979; Sigmundi et al., 1980). It is significant that the observations made by an inexperienced observer also correlate highly.

Groups FC and BC both showed a stable barpress baseline at the beginning of testing. The groups did not differ in barpressing rate during the 60 -sec pre-CS period $[F(1,14)<1]$. No freezing was observed at this time. The barpress baseline did detect a difference between the groups in suppression to the CS. Groups BC and FC showed mean suppression ratios (Annau \& Kamin, 1961) of .41 and .07 , respectively, during the test. These differed reliably $[F(1,14)=18.75, p<.01]$. The groups also differed reliably in terms of the number of barpresses emitted during the $\operatorname{CS}[F(1,14)=6.23$, $\mathrm{p}<.05\}$.

The percentages of behavior samples that were taken during the CS and recorded as freezing, barpressing, and activity combined with food-cup behavior are shown in Figure 1 . The animals appeared to spend relatively more time engaged in active behaviors other than barpressing during the test. Approximately $7 \%$ of the combined activity scores shown were food-cup behaviors. Of central interest, Group FC showed reliably more freezing in the presence of the CS than did Group BC $[F(1,14)=$ $10.37, \mathrm{p}<.01]$. When data from both groups were combined, freezing was reliably correlated with the barpress suppression ratios $[\mathrm{r}(15)=-.82, \mathrm{p}<.01]$. Freezing was also correlated with the number of barpresses made during the $\operatorname{CS}[\mathrm{r}(15)=-.63, \mathrm{p}<.01]$. These correlations suggest that when the barpress baseline is suppressed, the rat is indeed freezing. Both measures of barpress suppression were correlated with

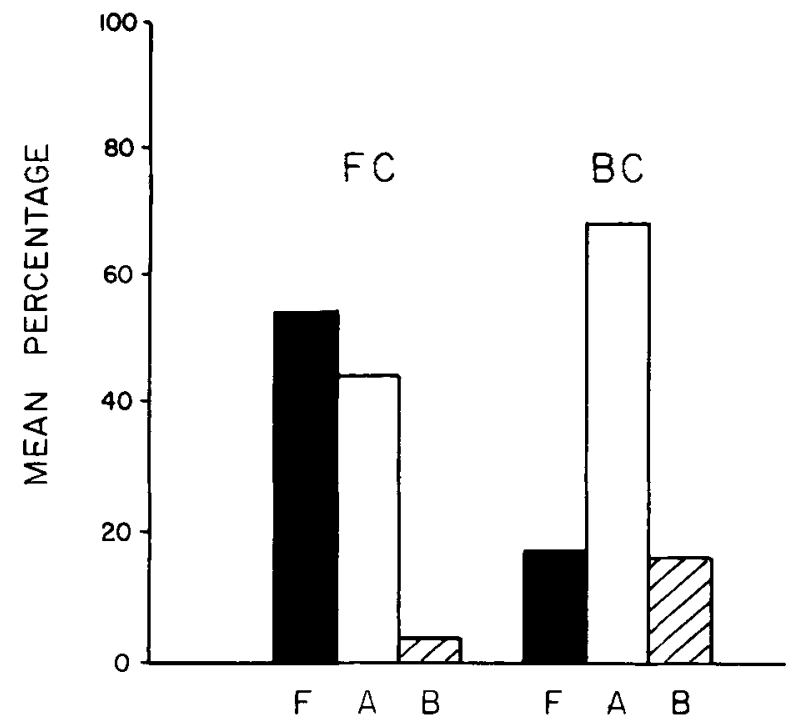

Figure 1. Percentage of behavior observed during the $\mathrm{CS}$ that was freezing ( $F$ ), activity combined with food-cup behavior (A). and barpressing (B) for the groups in Experiment 1. freezing within Group FC [suppression ratios, $r(7)=$ $-.93, \mathrm{p}<.01 ;$ number of barpresses, $\mathrm{r}(7)=-.82$, $p<.01]$. The correlation of these measures with freezing within Group BC, however, did not reach the conventional level of statistical reliability [suppression ratios, $r(7)=-.44, p>.10$; number of barpresses, $r(7)=-.57$, $p>.10]$. A correlation between freezing and suppression was not expected in Group BC if the backward control procedure did not produce conditioning to the CS.

As an aid in comparing the different measures of conditioning that were available in the present experiment, we described the degree to which each dependent measure was associated with the independent variable as a point biserial coefficient, $\mathrm{r}_{\mathrm{pb}}$. Point biserial coefficients can be derived directly from the $F$ ratios $\left[\mathrm{r}_{\mathrm{pb}}{ }^{2}=\mathrm{F} /(\mathrm{F}+\mathrm{df})\right]$, and provide estimates of the sensitivity of each of the measures of conditioning. When the barpress suppression ratio was the measure of conditioning, $\mathrm{r}_{\mathrm{pb}}=.76$. For the number of barpresses emitted during the $\mathrm{CS}, \mathrm{r}_{\mathrm{pb}}=.55$, and for freezing as assayed by the time-sampling method, $r_{p b}=.65$. Thus, freezing measured by the time-sampling method compared favorably with more conventional loss-of-barpress baseline measures in sensitivity to the effects of the conditioning treatment.

\section{EXPERIMENT 2}

The suppressive effects of shock CSs are not limited to appetitive operant barpressing. Leaf and Muller (1965) introduced a measure of aversive conditioning that involved the suppression of the consummatory licking of a $16 \%$ sucrose solution. A major attraction of this baseline is that it does not require initial training of the index response. Although lick suppression is often expressed in terms of the standard suppression ratio (e.g., Mackintosh, 1975), the measure favored by Leaf and Leaf (1966) was the time required for licking to resume after it was suppressed by the CS. In the present study, we examined the relation of lick suppression to freezing using the procedures introduced by Leaf and Leaf (1966) and Leaf and Muller (1965).

\section{Method}

Subjects and Apparatus. The animals were 20 female rats from the same stock as before, approximately 90 days old at the start of the experiment. They were housed in the same manner, but the deprivation conditions used in this experiment were different (see below).

The conditioning boxes used in the preceding experiment were modified. An insulated drinking tube was centered in a side wall, $3 \mathrm{~cm}$ above the floor and extending $3 \mathrm{~cm}$ into the chamber. The licking of a $16 \%$ sucrose solution from the tube was monitored with a drinkometer circuit. The $3,300-\mathrm{Hz}$ tone $\mathrm{CS}$ was presented at $84 \mathrm{~dB}$ (re $20 / \mu \mathrm{N} / \mathrm{m}^{2}$ ) against a background noise level of $60 \mathrm{~dB}$. The US was again $.5 \mathrm{sec}$ of a $1-\mathrm{mA}$ scrambled footshock.

Procedure. The animals' first exposure to the apparatus was during a 100 -min conditioning session in which a 10 -sec presen- 
tation of the tone CS was paired with shock 20 times. One group of animals, Group FC $(n=10)$, received forward pairings of the CS and shock, while the other group, Group BC, received backward pairings of these stimuli. The intertrial interval was fixed at $5 \mathrm{~min}$. Immediately following the conditioning session, all animals were returned to their home cages and deprived of food and water for $48 \mathrm{~h}$. Each rat was then tested individually at the end of the deprivation period. The animal was placed in the box with the drinking tube now available. The CS was presented upon the 100th lick recorded by the drinkometer; the interval of time to CS onset was recorded. The CS remained on for the remainder of the test session, which ended after the CS had remained on for $10 \mathrm{~min}$ and the animal had emitted another 100 licks. Licking during the CS was monitored on a chart recorder. An observer sampled each animal's behavior every $3 \mathrm{sec}$ during the CS. Behavior was recorded as freezing, drinking, or activity (see Table 1).

\section{Results}

The effect of the CS was to strongly suppress licking in Group FC. Group FC took 9.22 min to resume licking (make 100 licks in the presence of the CS), while Group $B C$ took only $2.43 \mathrm{~min}[\mathrm{~F}(1,18)=5.00, \mathrm{p}<.05]$. It is possible to calculate the usual $B /(A+B)$ suppression ratio (where $A$ and $B$ are lick rates) with the procedure of Leaf and Leaf (1966), but the ratio has to be modified slightly because there is no direct record of $A$, the lick rate immediately prior to the CS. Instead, we let A equal the pre-CS lick rate as determined by the 100 licks made prior to the CS divided by the latency to CS onset. B equaled the lick rate during the 1 st minute of the CS. The resulting ratios for Groups FC and BC were .10 and .82 , respectively. These values are somewhat inflated because the pre-CS lick rate (A) was depressed since no animal began licking immediately at the start of the session. Nonetheless, Group FC was reliably more suppressed than Group BC $[F(1,18)=$ $7.85, \mathrm{p}<.025]$. The groups also differed reliably in the number of licks made during the 1st minute of the $\operatorname{CS}[F(1,18)=10.43, p<.005]$.

The observational data are shown in Figure 2, where we have plotted the percentages of the behavior samples that were coded as drinking, activity, and freezing during the 1st minute of the CS. The 1st minute was chosen arbitrarily, and conclusions based upon it are consistent with analyses over other time intervals. Group FC froze reliably more than Group BC $[F(1,18)=$ $23.55, \mathrm{p}<.005]$. Moreover, loss of the lick baseline was related to freezing evoked by the CS. When data from both groups were combined, freezing was reliably correlated with each of the measures of lick suppression [the latency to resume drinking, $\mathrm{r}(19)=+.74, \mathrm{p}<.01$; the suppression ratios, $\mathrm{r}(19)=-.78, \mathrm{p}<.01 ;$ number of licks during the 1 st minute of the CS, $r(19)=-.76$, $\mathrm{p}<.01]$. Freezing was also reliably correlated with each of these measures within Group FC [the latency to resume drinking, $\mathrm{r}(9)=+.64, \mathrm{p}<.05$; the suppression ratios, $\mathrm{r}(9)=-.84, \mathrm{p}<.01$; number of licks during the 1 st minute of the CS, $r(9)=-.74, p<.01]$. Within Group BC, whether or not the correlation between

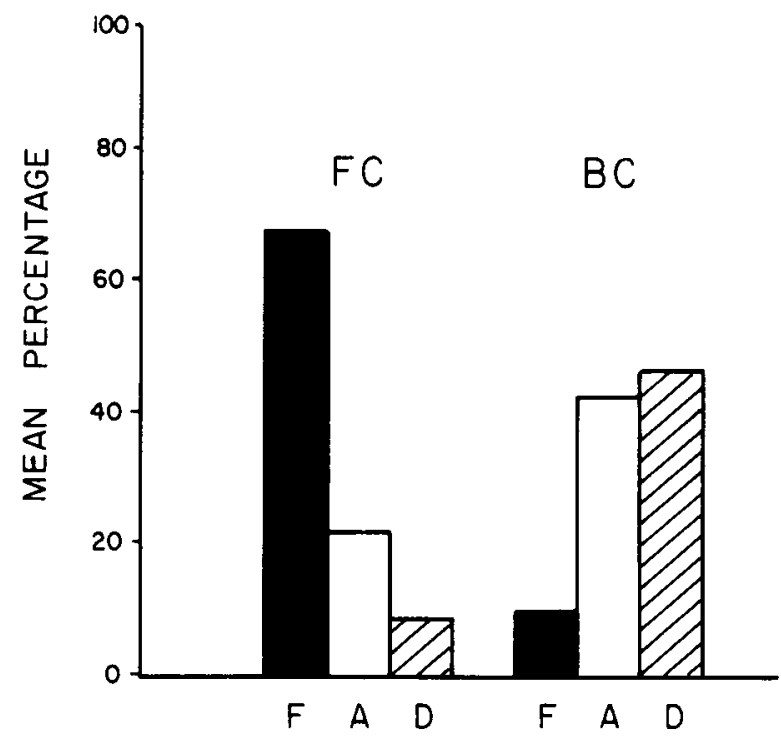

Figure 2. Percentage of behavior observed during the lst minute of the CS that was freezing (F), activity (A), and drinking (D) for the groups in Experiment 2.

freezing and these measures was reliable appeared to depend upon the measure in question [the latency to resume drinking, $\mathrm{r}(9)=+.74, \mathrm{p}<.01$; the suppression ratios, $\mathrm{r}(9)=-.32, \mathrm{p}>.10$; number of licks during the 1 st minute of the CS, $\mathrm{r}(9)=-.53, .05<\mathrm{p}<.10$ ]. A correlation in Group BC was not expected if the backward control procedure had failed to produce conditioning to the CS.

Point biserial coefficients were obtained from the analyses of the various indices of conditioning. For the time-to-resume-licking measure, $\mathrm{r}_{\mathrm{pb}}=.47$; for the lick suppression ratios, $\mathrm{r}_{\mathrm{pb}}=.55$; and for the number of licks measure, $\mathrm{r}_{\mathrm{pb}}=.60$. The time-sampled measure of freezing appears to have been quite sensitive to the effects of conditioning $\left(\mathrm{r}_{\mathrm{pb}}=.75\right)$. As in the preceding experiment, the amount of freezing recorded by direct observation appears to be comparable to loss-of-baseline indices of conditioning in its sensitivity to the effects of the experimental manipulation.

\section{EXPERIMENT 3}

The preceding studies examined the relation of freezing to behavioral baselines maintained by appetitive incentives. In the final study, we merely document that the presence of an explicit incentive is not a prerequisite for the behavioral measurement of aversive conditioning. Here we examine spontaneous activity as a baseline for aversive conditioning. This baseline has been used before (e.g., Bouton \& Bolles, 1979; Davitz, Mason, Mowrer, \& Viek, 1957) but has received relatively little attention in the literature. In the present study, we used a procedure following that developed by Leaf and Muller (1965) for lick suppression. 


\section{Method}

Subjects and Apparatus. The subjects were 16 female rats from the same stock as before, approximately 100 days old at the start of the experiment. They were housed as were the animals in the preceding experiments; however, food and water were available on an ad-lib basis in the home cage throughout the experiment.

The apparatus was the same as that used in the preceding experiment, with the drinking tube removed. Since it was desirable to correlate freezing with the loss of an automated measure of activity, the drinking tube was replaced by a photocell unit, the light source and photocell of which were centered in the side walls, $3 \mathrm{~cm}$ above the floor. Interruptions of the photocell beam were recorded by chart recorder. The CS and US were the same as in the preceding experiment.

Procedure. The procedure followed that of Experiment 2 in nearly all respects. The animals' first exposure to the apparatus was during the $100-\mathrm{min}$ conditioning session. At that time, 10 -sec presentations of the CS were paired with the US 20 times. Group FC $(n=8)$ received forward pairings of these stimuli, and Group $\mathrm{BC}$ received them in a backward order. Testing was conducted in an arbitrarily designated box $48 \mathrm{~h}$ later; the animals were not deprived. The CS was presented upon the 10 th photocell-beam interruption and remained on for the rest of the session, which ended after the CS had been on $10 \mathrm{~min}$ and the animal had interrupted the beam 10 more times. Behavior was recorded by an observer during the $\mathrm{CS}$ and coded as either freezing or activity (Table 1 ).

\section{Results}

Freezing and activity observed during the 1 st minute of the CS are shown in Figure 3. Once again, our choice of the 1st minute is arbitrary and the conclusions based upon it are consistent with analyses over other time intervals. As suggested by the figure, Group FC froze reliably more than Group $B C[F(1,14)=16.95, p<.005]$. The point biserial coefficient $\left(\mathrm{r}_{\mathrm{pb}}\right)$ based upon this analysis was .74 . Freezing measured by the time-sampling procedure appears to be a sensitive index of conditioning

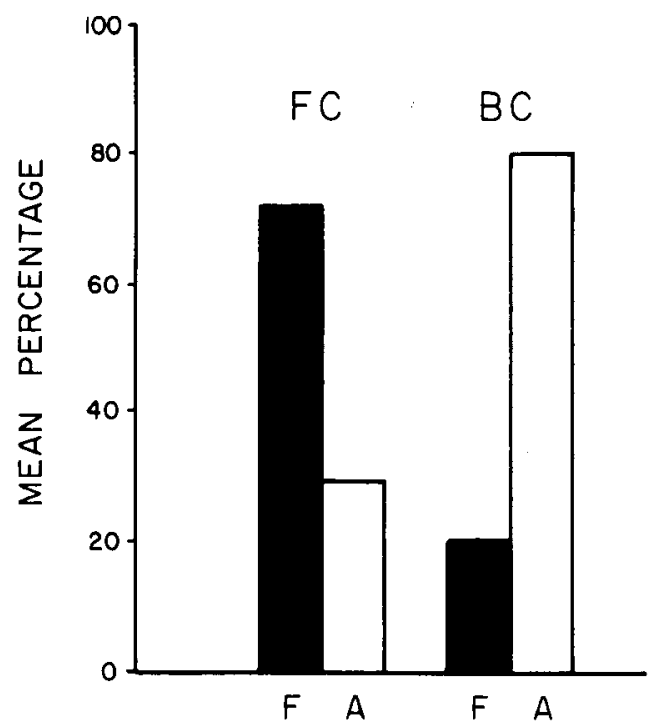

Figure 3. Percentage of behavior observed during the lst minute of the $C S$ that was freezing (F) or activity (A) for the groups in Experimenı 3. in the absence of an explicit incentive supporting another behavior.

The single photocell used in this study as an automated measure of activity did not produce enough data to make analyses over short time intervals meaningful. However, Group FC took an average of $10.92 \mathrm{~min}$ to recover baseline (make 10 beam interruptions during the CS), while Group BC took only $4.56 \mathrm{~min}$. The groups differed reliably on this measure $[F(1,14)=6.21$, $\mathrm{p}<.05$ ]. In addition, when the photocell data were analyzed over the first $5 \mathrm{~min}$ of the CS, Group FC made reliably fewer beam interruptions than Group BC $[F(1,14)=8.75, p<.05]$. When the data for both groups were considered, activity as measured by the photocell at the 5 -min interval was reliably correlated with freezing $[\mathrm{r}(15)=-.82, \mathrm{p}<.01]$. The correlation held within both Group FC and Group BC [rs(7) = -.81 and -.68 , respectively, ps $<.05$ ]

\section{GENERAL DISCUSSION}

Freezing was reliably correlated with the suppression that a forward-conditioned, auditory CS produced on three different baselines: a food-reinforced operant baseline, a consummatory lick baseline, and a spontaneous activity baseline. These results suggest that the rat's defensive behavior repertoire is an important feature of this set of aversive conditioning situations. In the barpress and lick situations, freezing was correlated with baseline suppression when suppression was expressed in several possible ways. And, in every case, individual differences in baseline suppression to the forwardconditioned CS were correlated with individual differences in freezing. These data begin to specify the relationship between freezing and the conventional measures of conditioning.

Baseline suppression might not be so highly correlated with freezing in environments that provide stimulus support for other defensive behaviors, such as running away (see Blanchard \& Blanchard, 1971). It is also possible that under different conditions, such as conditions that produce levels of suppression different from those studied here, we would not find baseline suppression so highly correlated with freezing. However, the literature indicates that freezing varies with many of the Pavlovian parameters that also affect conditioned suppression (e.g., Blanchard \& Blanchard, 1969; Davitz et al., 1957; Fanselow \& Bolles, 1979a; Sigmundi et al., 1980). This suggests that freezing may, in fact, covary with baseline suppression over a wide range of conditions. Although this proposition remains to be more fully explored, the present data begin to suggest that, in a representative test environment and with procedures that produced representative levels of suppression, the animal that shows baseline suppression is indeed freezing. 
The fact that individual differences in freezing correlated with the present treatment conditions and with scores on widely accepted measures of conditioning suggests that freezing might be useful as a measure of conditioning. This conclusion is supported by the facts that freezing is responsive to many of the parameters of conditioning and that, as reported here, the direct measure of freezing is as sensitive to the effects of conditioning as the more traditional indices of fear. The freezing measure has the practical advantage that it does not require baseline training. Moreover, unlike traditional indices of conditioning that focus on what the animal is not doing, only measures like the freezing measure, which focus directly on behavior evoked by the $\mathrm{CS}$, can address the issue of response selection in conditioning (see Sigmundi et al., 1980). Thus, the freezing measure may offer an equally sensitive and more convenient method for studying the variables affecting conditioning, and may confer unique advantages as well.

Like the finding that localized, visual CSs may evoke withdrawal behaviors that compete with an appetitive baseline (Karpicke et al., 1977), the finding that CSevoked freezing correlates with suppression is consistent with competing response theories of conditioned suppression (e.g., Kamin, 1965; McAllister \& McAllister, 1971). However, the present findings do not identify the exact locus of the "competition" that causes suppression. Based on their finding that higher appetitive motivation supporting the baseline reduces the magnitude of suppression, Millenson and de Villiers (1972) have theorized that the competition is motivational. However, it has been argued that this finding is difficult to interpret because of scaling problems (Dickinson \& Pearce, 1977). And it can be interpreted in other ways: for example, increased appetitive motivation may merely produce stronger appetitive behavior that competes more effectively with defensive behavior evoked by the CS. Like those of Millenson and de Villiers, the present results do not constitute a critical test of the motivational account of conditioned suppression. But they do suggest that a motivational account should recognize the possible role that defensive behaviors can play in the suppression of appetitive behavior.

\section{REFERENCES}

Avil. Z.. \& KIMIN. L. J. The conditioned emotional response as a function of intensity of the US. Journal of Comparative and Phusiological Psychologv, 1961, 54, 428-432.

Bi.AKKMAN, D. Conditioned suppression and the effects of classical conditioning on operant behavior. $\ln$ W. K. Honig \& J. E. R. Staddon (Eds.). Handhook of operant hehavior. Englewood Cliffs. N.J: Prentice-Hall, 1977.

Blanchari), R. J.. \& Bian(hari), D. C. Crouching as an index of fear. Journal of Comparative and Physiological Prychology, 1969.67.370).375.

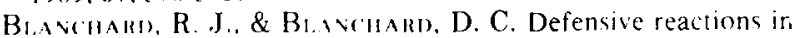
the altimu rat Learnme and Motivation, 1971. 2. 351-362.

Burtas. R. C.. \& Comstrk. A. C. The effect of predictive cues on freezing in rats. Animal Learnine \& Behavior. 1976. 4 . 6-8.

Bol,k.s. R. C., \& Ril.fy, A. L. Freezing as an aroidance response: Another look at the operant-respondent distinction. Learning and Motivation, 1973, 4, 268-275.

Bouton. M. E., \& Bol.c.s. R. C. Contextual control of the extinction of conditioned fear. Learning and Motivation. 1979. $10,445-466$

Davitz, J. R., Mason, D. J.. Mowrer, O, H., \& VikK, P. Conditioning of fear: A function of the delay of reinforcement. American Journal of Psuchology, 1957, 70, 69-74.

Dickinson, A., \& Pearce. J. M. Inhibitory interactions between appetitive and aversive stimuli. Psychological Bulletin, 1977. 84. 690-711.

Estes. W. K., \& Skinnkr, B. F. Some quantitative properties of anxicty. Journal of Experimental Psychologv. 1941. 29. $390-400$.

Fansel.ow, M. S.. \& Boll...s. R. C. Naloxone and shock-elicited freezing in the rat. Journal of Comparative and Physiological Psuchology, 1979, 93, 736-744. (a)

Fanserow, M. S.. \& Boll.s. R. C. Triggering of the endorphin analgesic reaction by a cue previously associated with shock: Reversal by naloxone. Bulletin of the Psychonomic Society. 1979, 14, 88-90. (b)

Heтн, C. D. Simultaneous and backward fear conditioning as a function of number of CS-UCS pairings. Journal of Experimental Pruchology: Animal Behavior Processes, 1976, 2, 117-129.

Hoffman, H. S., \& Barrirt, J. Overt activity during conditioned suppression: A search for punishment artifacts. Journal of the Experimental Analysis of Behavior, 1971, 16, 343-348.

Hunt, H. F.. \& Brady, J. V. Some effects of punishment and intercurrent "anxiety" on a simple operant, Journal of Comparative and Phvsiological Psvchologv, 1955, 48, 305-310.

Kamin. L. J. Temporal and intensity characteristics of the conditioned stimulus. In W. F. Prokasy (Ed.). Classical conditioning. New York: Appleton-Ceniury-Crofts, 1965.

Karpicke, J., Christopli. G., Priterson, G., \& Hearst, E. Signal location and posilive versus negative conditioned suppression in the rat. Journal of Experimental Psvchologv: Animal Behavior Processes, 1977, 3, 105-118.

Leaf, R. C., \& Leaf, S. R. P. Recovery time as a measure of degree of conditioned suppression. Psychological Reports, $1966,18,265-266$.

Lfaf, R. C., \& Muller, S. A. Simple method for CER conditioning and measurement. Psychological Reports, 1965, 17, 211.215 .

Mackintosi, N. J. Blocking of conditioned suppression: Role of the first compound trial. Journal of Experimental Psychology: Animal Behavior Processes, 1975, 1, 335-345

McAlister. W. R., \& McAlister, D. E. Behavioral measurement of conditioned fear. In F. R. Brush (Ed.), Aversive conditioning and learning. New York: Academic Press, 1971.

Mill,enson, J. R., \& DE VIl,.it.Rs, P. A. Motivational properties of conditioned anxiety. In R. M. Gilbert \& J. R. Millenson (Eds,), Reinforcement: Behavioral analyses. New York: Academic Press. 1972.

Pinel, J. P. J., \& Treit, D. Burying as a defensive response in rats. Journal of Comparative and Phusiological Psycholog. 1978, 92, 708-712.

Sigmundi, R. A., Bouton, M. E., \& Bols.s, R. C. Conditioned freezing in the rat as a function of shock intensity and CS modality. Bulletin of the Psychonomic Society, 1980. 15, 254-256.

Stein, N., Hofrman, H. S., \& StrtT, C. Collateral behavior of the pigeon during conditioned suppression of keypecking. Journal of the Experimental Analvsis of Behavior, 1971, 15. 83-93.

(Received for publication January 21. 1980): revision accepted May 15. 19817.) 